\title{
Impromptu. Aproximaciones a la performance poética
}

\author{
Adrián Cangi \\ Universidad de Buenos Aires \\ adriancangi@hotmail.com \\ a Roberto Echavarren y \\ Tamara Kamenszain
}

\section{Composibilidad}

La performance poética es un mixto y como tal una zona indiscernible donde se confunden tradiciones, aquella propia de la escritura poética y aquella otra de la performatividad escénica. Poema indica genéricamente un trabajo cerebral y por ello no menos corporal, una escritura en caverna, un cosmos reducido y recóndito de intensidades, de transparencias y opacidades que puede alcanzar en su extensión el gesto mínimo o el tamaño del mundo. Es el lugar de la lengua donde se ejerce y se radicaliza una proposición sobre el ser y sobre el tiempo, un vínculo entre palabra y experiencia. Cuando decimos que el poema indica un trabajo cerebral, pensamos que nuestro tiempo está definido por una ontología vitalista que afirma que aquello que se puede predicar del ser es el trabajo de su expresión. Tiempo de mónadas expresivas que inscriben la diferencia inmanente en su producción intensa. Poema es para este espíritu del tiempo una textura donde se opera por sustracción o por exceso, entre el azar y la determinación, entre lo finito y lo infinito, para presentar la tensión entre desorientación y orientación que imprime el acontecimiento en el ser. El acontecimiento inmanente es virtual, como lo ha señalado Deleuze, y no cesa de actualizarse en un estado 
de cosas, en una relación inestable entre el objeto y el sujeto que éste afecta y produce. Poema es el lugar de la lengua donde la inmanencia vital atraviesa un régimen de signos irrumpiendo en el movimiento de la gramática e inscribiéndose en ésta como procedimiento. Sin tensión entre vida y procedimiento no hay despliegue de la invención. Producir una composición poética es alcanzar un ritmo, un timbre, un tinte, un gesto, donde el yo es saturado de autoafección y sacado de su esquema sensorial. Performance es un juego de variabilidades escénicas, de estímulos locales, donde objetos, espacios, sonidos, se componen en un ejercicio de excepcionalidad. Sin la idea de un compuesto escénico y de un gesto de empeño lúdico en ebullición no es posible la performance. Ésta requiere construir figura y medio, cuerpo y espacio que determinan la escena. Echavarren dice que se trata de una "alegorización" donde los participantes destraban el comportamiento encontrando cada cual en el compuesto el margen de deseo. Entre el acting out de los cuerpos y el vehículo de los fetiches en juego que se prolongan en el espacio, se despliega lo englobante sónico e imagético propio de la performance.

La performance poética traiciona y potencia la tradición propiamente lingüística del poema y la propiamente escénica del teatro experimental del que proviene su emancipación. Poema y performance configuran "seres de sensación® con reglas expresivas propias, que producen pasajes secretos entre el cuerpo de la escritura y el de la presentación escénica, entre la intimidad del poema y la pública "histéresis" performática. En el juego entre ambos se tensan ritmos y se confunden territorios. Todo conduce a la vibración del entrelugar, dominio del @cuerpo vibrátil@ o @ser de sensación๑, donde se amplían los dones poéticos y escénicos a expensas de cualquier pretendida unidad. El entrelugar en vibración configura un mixto que ya no puede ser definido por las propiedades lingüísticas o escénicas, sino por el principio de desorganización general que lo vibrátil imprime en las partes componentes. Los estímulos inadecuados e integrales propios del gesto de la performance hacen añicos la unidad del ritmo que convoca el poema, al mismo tiempo que potencian zonas imagéticas o iluminan fragmentos inesperados del mismo. La performance poética produce un borramiento de fronteras y un tránsito, donde se ha histerizado el poema y poematizado la histeria, destituyendo todo principio de representación. Es del orden 
del acontecimiento, es decir, de la precariedad de lo que adviene e indica sobre lo que quiere decir "pasa algo". ¿Es posible que éste sea el radical sentido del arte: el de señalar el recorrido de una potencia singular que va al encuentro del acontecimiento?

La performance poética es un fuera de lugar cuyo poder reside en la relación y en la conversión. Relación de compuestos disímiles y conversión de los componentes en un espacio desorientante. Si pensamos en término de sus partes el mixto de sensación llamado performance poética es la puesta en suspensión del orden de las cosas y de las predicaciones. Aquello que define la propiedad del mixto es el desplazamiento de sus componentes, la condición de volver a cada uno extranjero en el compuesto. El azar que mueve la desviación de la performance poética reivindica su condición ๑atópica๑. Todo lo que puede predicarse sobre ésta comienza en un fuera de lugar, es decir, en el pleno vuelco hacia un suplemento o un excedente en acto de la representación. En la performance poética triunfa el mixto o el monstruo que trae a la presencia la anomalía y autonomía de los rasgos expresivos. El entrelugar es un fuera de lugar o un fuera de género y produce lo sensible incondicionado que vibra como tensión y desfiguración, como catástrofe de las tradiciones expresivas, confundiendo el plano de contenido y de expresión propios del poema y de la performance. Por ello, el mixto constituye un impromptu, por su esencial fragilidad, improvisación y finitud. En la tradición musical, se trata de una pieza pequeña compuesta sobre la marcha y sin excesiva preparación. Fragilidad, improvisación y finitud presentan una obra proceso, donde el arte pensándose a sí mismo, revisa sus límites.

\section{Performatividad}

Muchos autores han trabajado la relación entre performance y rituales cotidianos. Austin, Goffman, Singer, Turner, Myerhoff, Kosofsky, Sedwick, Schechner y Butler han elaborado aproximaciones entre prácticas determinadas y repeticiones que fijan comportamientos. Schechner ha sostenido que el acto performativo se confunde con lo que la gente hace representando sus identidades sociales y/o personales. Performance, en la tradición del interaccionismo simbólico, ๑es donde la gente actúa sus vidas de 
veras®. Schechner señala que incluso para Butler el género mismo es performativo, es decir, que constituye la identidad que aparenta ser. El núcleo de la teoría de Butler se sostiene en la idea de que si existe libertad de acción, ésta debe buscarse, paradójicamente, en las posibilidades que ofrece la apropiación obligada de la ley reguladora, la materialización de esa ley, la apropiación impuesta y la identificación con tales demandas normativas. El cuerpo sexuado acciona en observancia y en disimulación a la ley, produciendo efectos materiales. Para la autora, solo la libertad de acción se inscribe en el mundo con relación a la matriz de la ley y como demarcación, resistencia e invención de efectos materiales vívidos y necesarios. De modo que para Butler, Schechner y Sedwick, entre otros, la performatividad no es un acto singular porque siempre es la reiteración de una norma o un conjunto de normas y, en la medida en que adquiera la condición de acto en el presente, oculta o disimula las convenciones de las que es una repetición.

Butler agrega que el acto performativo no es primariamente teatral. Su teatralidad se produce en la medida en que permanezca disimulada su historicidad. Aquello que se sostiene de Austin a Derrida, es que los efectos discursivos son performativos cuando vinculan el acto de habla o el sistema de enunciación a la producción de lo que nombran o enuncian. La norma habita en los efectos discursivos, en su iteración como matriz de identificación de conductas y deimperativos en la constitución delyo. Para Butler, hacer ๑desviar@ o @derivar@ comportamientos es condición de procesos históricos en relación con la ley y su sedimentación. Por ello dirá que @la materialización de comportamientos será una adquisición del ser mediante citas del poderø. El voluntarismo no tiene sentido en esta tradición de pensamiento porque se considera que el sujeto de la resistencia inventiva ha sido producido y habilitado por las normas iterativas. La inmanencia del poder es iterativa, reiterativa, rearticuladora y elimina toda reflexión sobre un sujeto que escoge ajeno al discurso del poder o a las hegemonías materializadas por la norma y sus procesos identificatorios. Los cuerpos abyectos, sostiene Butler, no son considerados cuerpos. Por ello, el concepto de performatividad es utilizado por la autora para comprender el dominio simbólico y la construcción de género. Lo performativo, para este pensamiento, no debe entenderse como un libre juego ni 
como una autorepresentación teatral y nada tiene que ver con el sentido de realización. No emerge de un acto único sino de un ritual repetible que logra su efecto ๑naturalizándose® culturalmente en el cuerpo. En este sentido, la performatividad como repetición ritual habilita al sujeto y constituye su condición temporal.

¿De qué modo podría vincularse esta noción de lo performativo con la práctica escénica de la performance? El dominio del arte abre un quiasmo en la repetición-variación de las matrices del poder. La creación de estímulos inadecuados propio de la performance no solo hiperboliza o excede las normas o las parodia, como sostiene Butler, sino que crea una imagen desfasada o un margen de deseo que al singularizarse desgasta lo reiterativo y rearticulador de la matriz. El dominio del arte convoca potencias inorgánicas, figuras como máquinas célibes, espacios cualesquiera indeterminados; es decir, lo sensible incondicionado donde resulta posible y necesario pensar la irrupción de la diferencia eficiente. Para Butler, el quiebre en la repetición es el ๑espacio ocasional® en el que habita el cuerpo abyecto, que busca abrir el futuro haciendo proliferar diversas configuraciones de género y desestabilizando la idea de identidad sustantiva. Para nosotros, se trata del dominio de la imagen por venir, indeterminada como un ๑ser cualsea® o como sostiene Agamben: ๑la singularidad que expuesta como tal es cualse-quiera॰.

\section{Performance poética}

Por donde lo miremos la performance que narra y presenta el poema o lo poemático del gesto escénico performático son perversos: desmantelan representaciones y hacen pasar conexiones en variabilidad continua por los cuerpos para ponerlos a merced de estímulos inadecuados. La herencia de la crueldad reclamada por Artaud, las conexiones inorgánicas de los maniquíes de Bruno Schulz, el desenmascaramiento ritual de Kantor, la liberación de las ataduras escénicas de Bob Wilson o del Living theater, abren modos performáticos más allá del organismo y de la representación que el poema o la puesta en escena capturan como procedimientos expresivos para dar presencia a unos ritmos y a unas figuras. Una performance siempre es única, singular e incomparable. Al borde 
de la furia del cuerpo como en Bene o de su sustracción como en Beckett, promete un alumbramiento, un compuesto, una ๑costra viviente@ en la voz del poeta o en el gesto escénico, más del orden de una ๑cosa que siente® o de un ๑ser de sensación® que de un organismo vital. Nunca es plenamente mimética sino perdería su arista afilada y más que cortar se volvería gesto cultual y cultural rudimentario. No vitalizaría ningún enclave. Aurática y atlética convoca la fusión del organismo con los devenires inorgánicos y como un pájaro mecánico o una @máquina de gorjear@ marca su territorio y define su autonomía expresiva, imponiendo un ritmo desigual e inconmensurable a las conductas y rituales de la vida real. De este modo, impregna la performance la existencia entera de estímulos inadecuados, sobrehumanos o infrahumanos, buceando en la excitación de los sonidos, los espacios y los objetos.

Schechner piensa la práctica performativa como una recuperación de comportamientos pasados, como herencia ritual y transmisión testimonial, como actualización y restauración de la memoria cultural del cuerpo y plena definición de sus propiedades y valores. La performance poética, a diferencia de este pensamiento, es del orden de un impromptu o de un entrenamiento, no de una inmediatez. Es una diferencia eficiente en el orden de las repeticiones, una actividad escénica contrahecha o deshecha frente a los rituales de la vida cotidiana. Schechner resulta un defensor de la antropología como medida de los movimientos de expresión porque disuelve los límites entre comportamientos corrientes, habituales, estereotipados y actos de excepcionalidad, impregnando la existencia entera de acciones performáticas.

Releo el poema ensayo de Godard llamado ejercicio 174, JLG/ JLG donde dice: “(...)

il y a la règle/ ça va/ il y a/ l'exception/ ça va/ la règle/ c'est la culture/ non/ il y a la culture/ que est de la règle/ il y a l'exception/ qui est de l'art/ qui fait parti de l'art/ tous disent la règle/ (...)๑. La poética del autorretrato de Godard cuestiona las ideas de Schechner, para quien performance es herencia actualizada y restaurada de la memoria cultural. Memoria reglada. Para el teórico neoyorquino la belleza se encuentra coagulada en el estereotipo y de ello depende la restauración de la memoria en el cuerpo y todas las variaciones posibles entre el principio de realidad y la ficción. La excepción 
atlética que plantea Godard por vías del arte es un quiasmo en la cultura, una diferencia singular e incomparable, una poética como bisturí que excava en las repeticiones estereotipadas para extraer de ellas, no tanto lo que queda del pasado como todo lo que se puede inventar hacia el futuro. La noción de cultura para Godard, como actualización y restauración, es un desierto sin excepciones y un espacio de naturaleza nostálgico. La afirmación performativa es la capacidad poética para crear futuro haciendo añicos las mallas sombrías de la insistencia cultural e inventando formas por venir.

¿Acaso no se trataba de esto lo que reclamaron sin cesar Deleuze y Guattari con la creación de un acontecimiento que diera vida a un @pueblo que faltaba®; o Negri con la invocación positiva de una multitud plural de deseos capaz de constituirse en una presencia de resistencia común? ¿Acaso, tal vez, la fuerza del under o de la contracultura no imprimió la plena autonomía de los elementos escénicos operando una poética desde las potencias de expresión del cuerpo, diluyendo las sobredeterminaciones que pesaban sobre éste? La emergencia del under en los 70 y su proyección en las décadas siguientes desligaban al cuerpo de sus lugares institucionales para devolverlo contrahecho, deseante y político, creador de niveles de problematicidad subjetiva y de lenguajes que ritmaban otras temporalidades. La contracultura afirmaba ese pueblo que faltaba y una presencia de resistencia común proclamando una autoafección que saturando al yo creaba el acontecimiento de las cualidades liberadas del organismo, la identidad y la representación.

Los rituales de la cultura son una ventosa y las potencias performáticas del arte un bisturí. Tanto para Godard, como para Echavarren en Centralasia, la regla es la muerte y la excepción es resistencia del deseo que inventa sobre la agonía, y entiende que la imagen es creación pura del espíritu que guía la carne por senderos de una vestidura extraña, de un compuesto indiscernible. Si la performance no es superación de sí mismo y de los propios límites a través de estímulos inadecuados, la minusvalía sensorial de la cultura proyecta y programa mediante imágenes-relación las acciones y los efectos de los cuerpos. La sociedad contemporánea se desgarra entre el hastío y la invención, más allá de todo horizonte de humanismos extenuados. Solicita lo indiscernible tanto como lo irrepetible. Solicita el acontecimiento singular. El acontecimiento es 
lo que irrumpe en el acontecer cotidiano, es para la mirada como un "vidrio rojo cuadrangular", dice el poeta, capaz de transportarnos a nuevos valores y a siluetas indefinibles. Se trata de una presencia del orden del soploy del hechizo: un puro resplandor de inconveniencias.

Anoto un pasaje de Centralasia que irrumpe en el relato y donde el plano de contenido se confunde con el de expresión en la mostración de una figura de excepcionalidad, donde el fetiche trae a la presencia una voluntad para destrabar el comportamiento. ๑(...)/ Se dedicó a desatar las crenchas largas y negras/ una a una apartó y cortó las cintas/ que sujetaban el rodete/ y agitó la cabeza para hacer caer/ la cabellera suelta sobre sus espaldas/ con una gracia que recordaba la de un dandy/ ligeramente afeminado/ ๑); Pero cuánto pelo tienes!/ ¡En mi vida había visto tanto!®/ La almohadilla de pelo postizo que sostenía el moño/ ardía por la parte que se apoyaba en la cabeza./ Cuando no se ocupaba de peinar su cabello/ venía a sentarse conmigo./ Su lánguida y distinguida figura/ contrastaba con su porte flemático./ En su apariencia no había nada/ que me permitiese adivinar su naturaleza.๑ El efecto del acontecimiento performático narrado oscila entre lo posible y lo inacabado, es tan real como un elefante rosa y su extensión no dura más que el ritmo de su intensidad, el ritmo de agitación de una cabellera. Se trata, por fin, de una flagrante aparición, de un secreto relampagueante, de un enigma expresivo similar a una estalagmita y sin embargo, con la materialidad de una silueta que convoca un clímax de luz particular.

El paisaje de la aparición performática abre lo reducido y recóndito del organismo humano y se extiende por la fuerza inorgánica al universo. Su fuerza es como en el mito de Anfión, que con sus sonidos indujo a las piedras a unirse y a dar forma a los muros de Tebas y permitió a Schelling pensar que el cuerpo no crea más que la imagen reducida de la tierra y del universo: una alegoría de lo inorgánico en lo orgánico. De aquella narración de principios del siglo XIX a la poética actual de Centralasia, de Schelling a Echavarren, se trazan los ritmos y territorios imagéticos por venir de la performance poética. La figura indecidible y el paisaje a imagen de esa figura, permiten transitar más allá de la diferencia entre lo natural y lo artificial para reconocer que la excitación indefinida nace entre lo uno y lo otro. La performance, como decíamos en el comienzo y corroboramos en la experiencia de lectura de Centralasia, 
convoca un ๑ser de sensación๑, una metamorfosis temporal que hace visible, que ensancha el mundo de figuras y paisajes, manteniendo zonas inaccesibles que impresionan por sorpresa y viven como oscilación. Ni el más preciso de los lentes alejará definitivamente la confusión que toda súbita presencia excepcional desencadena. El poema seguirá siendo un asunto cerebral que inventa un cuerpo; la performance poética un asunto corporal que orienta al cerebro. Entre ambos, la inestabilidad creadora. El último párrafo de Centralasia anota: "En la inestabilidad de todo/ el tiempo que se rompe se vuelve mi maestro." 